\title{
Attenuation of the Airway and Cardiovascular Responses to Extubation in Chronic Smokers by Prior Treatment with Dexmedetomidine, Fentanyl, and their Combination
}

\author{
Naglaa A. Ahmed, Ashraf M. Yehia, Ahmed H. Mohamed, Asmaa Abdulwahhab* (D) \\ Department of Anesthesia and Pain Management, National Cancer Institute, Cairo University, Giza, Egypt
}

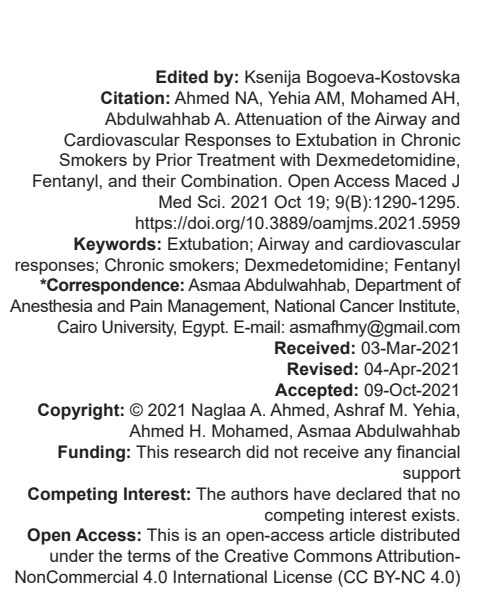

\section{Introduction}

Tracheal extubation is an essential procedure in anesthesia. While safely performed in a large proportion of cases, it can present significant challenges and complications when compared with intubation. This compares with the greater risk of aviation accidents during landing than during takeoff [1]. Complications associated with extubation can be severe, resulting in major morbidity and mortality [2].

Many smokers have hyperactive airway [3] and are prone to severe bronchospasm and desaturation during airway manipulation. The adrenergic receptors, particularly in the larynx, trachea, and bronchi [4], are stimulated by mechanical and chemical factors during extubation producing cardiovascular and respiratory reflex responses [5]. The plasma concentrations of noradrenaline and adrenaline will increase in chronic smokers causing tachycardia and hypertension which may result in complications such as cardiac failure, pulmonary edema, and cerebrovascular hemorrhage [4], [6].

Minimizing coughing on emergence should be emphasized, especially in particular surgeries to avoid complications, forexample, abdominalsurgeries(hematoma formation and suture disruption), thyroidectomy (surgical bleeding), carotid endarterectomy (neck hematoma), and intracranial surgery (intracerebral hemorrhage) [7]. Special techniques and pharmacological methods may help to decrease airway reflexes and hemodynamic responses during extubation. Drugs that have been recommended for the control of these airway and hemodynamic events including opioids, lignocaine, beta-blockers, calcium channel blockers, and alpha-2 agonists [7].

The objective of this randomized doubleblinded comparative study was to compare the effects of dexmedetomidine, fentanyl, and their combination on the attenuation of airway reflexes and hemodynamic responses to tracheal extubation in adults, chronic male cigarette smoking patients scheduled for elective surgeries (of average 2-3 h duration).

\section{Materials and Methods}

After approval from Ethics Committee at the National Cancer Institute, Cairo University, and obtaining written informed consent from patients, this 
randomized double-blinded comparative trial was conducted on 66 patients who were 20-60 years of age, chronic male smokers, and scheduled for elective abdominal surgeries.

\section{Inclusion criteria}

The following criteria were included in the study:

Chronic cigarette smokers (patients have smoked for 2 years at least and minimum consumption of 10 cigarettes/day) [8].

- American Society of Anesthesiologists (ASA) II.

- $\quad$ Body mass index of $\leq 30 \mathrm{~kg} / \mathrm{m}^{2}$.

\section{Exclusion criteria}

1- $\quad$ The following criteria were excluded from the study: History of opioid, sedative drugs, or medications affecting heart rate (HR) or blood pressure.

2- $\quad$ Morbid obesity.

3- $\quad$ Current upper respiratory infection

4- Hypovolemia

5- IHD

6- History of sleep apnea or expected difficult Intubation.

7- $\quad$ Emergency procedures.

8- $\quad$ Hepatic or renal impairment.

9- Drug allergy to dexmedetomidine or fentanyl.

\section{Sample size estimation}

Based on a previous study by Gosai et al. (2015) [8], and a large effect size of approximately 0.4 is expected. A total sample size of 66 (22 per group) will be sufficient to detect an effect size of 0.4 , a power of $80 \%$, and a significance level of $5 \%$. The sample size was calculated using the G*Power program (University of Düsseldorf, Düsseldorf, Germany) [9].

Eligible patients using the sealed envelope technique were divided randomly into three different groups (22 subjects each) receiving the study drug over $15 \mathrm{~min}$ :

- Group (A): Will receive dexmedetomidine 1 ug. $\mathrm{kg}^{-1}$ in $100 \mathrm{ml}$ normal saline (NS) intravenous (IV)

- Group (B): Will receive fentanyl citrate $1 \mathrm{ug} . \mathrm{kg}^{-1}$ in $100 \mathrm{ml}$ NS IV

Group (C): Will receive both dexmedetomidine $1 \mathrm{ug} . \mathrm{kg}^{-1}$ mixed with fentanyl $1 \mathrm{ug} . \mathrm{kg}^{-1}$ in $100 \mathrm{ml}$ NS IV.

A pre-anesthetic checkup was conducted and an in-depth history and complete physical examination were recorded. Routine investigations such as complete blood picture, blood grouping/typing, blood urea, and serum creatinine were done. Patients fulfilling inclusion criteria were informed about the procedure and its possible complications. Finally, a written consent was taken. Premedication with midazolam $0.05 \mathrm{mg} . \mathrm{kg}-1$, ondansetron $4 \mathrm{mg}$ and ranitidine $50 \mathrm{mg}$ IV followed by preoxygenation with $100 \%$ oxygen for 3 min was done. Induction with routine anesthetic technique was used using propofol $2 \mathrm{mg} \cdot \mathrm{kg}^{-1}$, fentanyl $2 \mathrm{ug} \cdot \mathrm{kg}^{-1}$, and atracurium $0.5 \mathrm{mg} . \mathrm{kg}^{-1}$ followed by intubation with an appropriate endotracheal tube (ETT). Anesthesia was maintained by oxygen/air mixture in a ratio of 40:60 and sevoflurane $2 \%$, atracurium $0.125 \mathrm{mg}$ at intervals with adequate volume replacement. Standard monitoring with electrocardiography, pulse oximetry $\left(\mathrm{SpO}_{2}\right)$, noninvasive BP, and capnograph was done.

About $15 \mathrm{~min}$ before the estimated end of surgery (or at the start of the closure of skin incision), the inhalation agent (sevoflurane) was stopped and the patient was kept on $100 \%$ oxygen. Ketorolac 30 mg slowly IV and paracetamol $1000 \mathrm{mg}$ IV infusion were given and the patients in each group received the specified solution IV over $15 \mathrm{~min}$.

Patients in Group A received dexmedetomidine 1 ug. $\mathrm{kg}^{-1} \mathrm{IV}$ in $100 \mathrm{ml} \mathrm{NS}$ over $15 \mathrm{~min}$, patients in Group B received Fentanyl $1 \mathrm{ug} . \mathrm{kg}^{-1}$ (IV) in $100 \mathrm{ml}$ NS over 15 min, while patients in Group C received both dexmedetomidine $1 \mathrm{ug} . \mathrm{kg}^{-1}$ mixed with fentanyl 1 ug. $\mathrm{kg}^{-1}$ in $100 \mathrm{ml} \mathrm{NS}$ over $15 \mathrm{~min}$.

When patients' spontaneous respiration was considered sufficient, being hemodynamically stable and ready to obey simple commands; the residual neuromuscular block was antagonized with neostigmine $0.05 \mathrm{mg} . \mathrm{kg}^{-1}$ and atropine $0.02 \mathrm{mg} . \mathrm{kg}^{-1}$. Oropharyngeal secretions were aspirated. The ETT was removed after the standards of extubation were fulfilled.

The anesthesiologist performing the extubation was blinded to the study drugs. HR, systolic BP, diastolic BP, and oxygen saturation were recorded at the beginning of bolus drug injection and thereafter at 1 , $3,5,10$, and $15 \mathrm{~min}$, also at the time of extubation and thereafter at 1,3 , and 5 min after extubation followed by every 5 min for $1 / 2 \mathrm{~h}$. Duration of anesthesia and surgery was noted.

Groups were monitored and compared for:

\section{Primary goals}

- $\quad$ Time to extubation (from inhaled anesthetic stop to ETT removal) was recorded.

Quality of extubation was evaluated immediately after extubation, employing a 5-point rating scale (Quality of Extubation Score) [10]:

1. No coughing

2. Smooth extubation, minimal coughing (1 or 2 times)

3. Moderate coughing (3 or 4 times) 
4. Severe coughing (5-10 times) and straining

5. Poor extubation, very uncomfortable (laryngospasm and coughing $>10$ times).

\section{Secondary goals}

- Hemodynamic responses (HR, systolic blood pressure [SBP], and diastolic blood pressure [DBP]).

- Incidence of complications in the form of laryngospasm, bronchospasm, desaturation, and bradycardia was defined as HR $<60 /$ min and treated with a rescue dose of injection atropine $0.6 \mathrm{mg}$ intravenously, tachycardia (being 20\% increase from baseline), hypertension (as either $20 \%$ increase from baseline or SBP >180 $\mathrm{mmHg}$ ), or hypotension (as $20 \%$ decrease from baseline or SBP $<80 \mathrm{mmHg}$ ).

- $\quad$ Post-operative agitation and sedation were evaluated on a 10 points scale (Richmond Agitation Sedation Scale [RASS] scale) [11]: (+4) Combative, (+3) very agitated, (+2) agitated, (+1) restless, (0) alert and calm, $(-1)$ drowsy, (-2) light sedation, (-3) moderate sedation, (-4) deep sedation, and (-5) unarousable.

\section{Statistical analysis}

Statistical analysis was done using $\mathrm{IBM}^{\odot}$ SPSS $^{\odot}$ Statistics version 23 (IBM $^{\odot}$ Corp., Armonk, NY, USA). Numerical data were expressed as mean and standard deviation or median and range as appropriate. Qualitative data were expressed as frequency and percentage. Chi-square test (Fisher's exact test) was used to examine the relation between qualitative variables. For quantitative data, comparison between the three groups was done using ANOVA test, then post hoc "Scheffe test" was used for pairwise comparison. Two-way ANOVA was invalid due to interaction, therefore, consecutive measures in each group were compared separately with ANOVA for repeated measures. This was followed by the appropriate post hoc test, with correction of the $p$-values. $p<0.05$ was considered statistically significant.

\section{Results}

The mean age of the study patients was 35.53 \pm 15.83 years, and there was no statistically significant difference in demographic data, ASA, or duration of surgery of the study group.

\section{Primary goals}

The time to extubation was significantly prolonged in the combined group (Group C). The quality of extubation score was significantly higher in the Fent group (Group-B).

\section{Secondary goals}

We had chosen six readings; baseline and $15 \mathrm{~min}$ after bolus injection, then immediately after extubation (at $0 \mathrm{~min}$ ), and 1, 3, and $5 \mathrm{~min}$ after extubation.

- $\quad$ Changes in HR

- $\quad$ Changes in SBP

- $\quad$ Changes in DBP

- Incidence of complications.

\section{Hypotension}

Hypotension was significantly (Table 1) more frequent in the combined group.

Table 1: Incidence of hypotension in the three study groups

\begin{tabular}{|c|c|c|c|c|}
\hline \multirow[t]{2}{*}{ Study groups } & \multicolumn{3}{|l|}{ Group } & \multirow[t]{2}{*}{ Total } \\
\hline & Dex group & Fentanyl group & Combined group & \\
\hline \multicolumn{5}{|l|}{ Hypotension } \\
\hline \multicolumn{5}{|l|}{ Yes } \\
\hline Count & 5 & 0 & 9 & 14 \\
\hline$\%$ within group & $22.7 \%$ & $0.0 \%$ & $40.9 \%$ & $21.2 \%$ \\
\hline \multicolumn{5}{|l|}{ No } \\
\hline Count & 17 & 22 & 13 & 52 \\
\hline$\%$ within group & $77.3 \%$ & $100.0 \%$ & $59.1 \%$ & $78.8 \%$ \\
\hline \multicolumn{5}{|l|}{ Total } \\
\hline Count & 22 & 22 & 22 & 66 \\
\hline$\%$ within group & $100.0 \%$ & $100.0 \%$ & $100.0 \%$ & $100.0 \%$ \\
\hline \multicolumn{5}{|l|}{ Chi-square tests } \\
\hline & Value & & $p$-value & \\
\hline Fisher's exact test & 12.188 & & 0.002 & \\
\hline
\end{tabular}

\section{Bradycardia}

Bradycardia was significantly more frequent in the combined group (Table 2).

Table 2: Incidence of bradycardia in the three study groups

\begin{tabular}{|c|c|c|c|c|}
\hline \multirow[t]{2}{*}{ Study groups } & \multicolumn{3}{|l|}{ Group } & \multirow[t]{2}{*}{ Total } \\
\hline & Dex group & Fentanyl group & Combined group & \\
\hline \multicolumn{5}{|l|}{ Bradycardia } \\
\hline \multicolumn{5}{|l|}{ Yes } \\
\hline Count & 2 & 1 & 15 & 18 \\
\hline$\%$ within group & $9.1 \%$ & $4.5 \%$ & $68.2 \%$ & $27.3 \%$ \\
\hline \multicolumn{5}{|l|}{ No } \\
\hline Count & 20 & 21 & 7 & 48 \\
\hline$\%$ within group & $90.9 \%$ & $95.5 \%$ & $31.8 \%$ & $72.7 \%$ \\
\hline \multicolumn{5}{|l|}{ Total } \\
\hline Count & 22 & 22 & 22 & 66 \\
\hline$\%$ within group & $100.0 \%$ & $100.0 \%$ & $100.0 \%$ & $100.0 \%$ \\
\hline \multicolumn{5}{|l|}{ Chi-square tests } \\
\hline & Value & & $p$-value & \\
\hline Pearson Chi-square & 27.958 & & 0.000 & \\
\hline
\end{tabular}

\section{Hypertension}

Hypertension was only monitored in two cases of the Fent group (Group B) (Table 3). 
Table 3: Incidence of hypertension in the three study groups

\begin{tabular}{|c|c|c|c|c|}
\hline \multirow[t]{2}{*}{ Study groups } & \multicolumn{3}{|l|}{ Group } & \multirow[t]{2}{*}{ Total } \\
\hline & Dex group & Fentanyl group & Combined group & \\
\hline \multicolumn{5}{|l|}{ Hypertension } \\
\hline \multicolumn{5}{|l|}{ Yes } \\
\hline Count & 0 & 2 & 0 & 2 \\
\hline$\%$ within group & $0.0 \%$ & $9.1 \%$ & $0.0 \%$ & $3.0 \%$ \\
\hline \multicolumn{5}{|l|}{ No } \\
\hline Count & 22 & 20 & 22 & \\
\hline$\%$ within group & $100.0 \%$ & $90.9 \%$ & $100.0 \%$ & $97.0 \%$ \\
\hline \multicolumn{5}{|l|}{ Total } \\
\hline Count & 22 & 22 & 22 & \\
\hline$\%$ within group & $100.0 \%$ & $100.0 \%$ & $100.0 \%$ & $100.0 \%$ \\
\hline \multicolumn{5}{|l|}{ Chi-square tests } \\
\hline & Value & & $p$-value & \\
\hline Fisher's exact test & 2.752 & & 0.323 & \\
\hline
\end{tabular}

\section{Tachycardia}

Tachycardia was significantly more frequent in the fentanyl group (Table 4).

Table 4: Incidence of tachycardia in the three study groups

\begin{tabular}{|c|c|c|c|c|}
\hline \multirow[t]{2}{*}{ Study groups } & \multicolumn{3}{|l|}{ Group } & \multirow[t]{2}{*}{ Total } \\
\hline & Dex group & Fentanyl group & Combined group & \\
\hline \multicolumn{5}{|l|}{ Tachycardia } \\
\hline \multicolumn{5}{|l|}{ Yes } \\
\hline Count & 0 & 11 & 0 & 11 \\
\hline$\%$ within group & $0.0 \%$ & $50.0 \%$ & $0.0 \%$ & $16.7 \%$ \\
\hline \multicolumn{5}{|l|}{ No } \\
\hline Count & 22 & 11 & 22 & 55 \\
\hline$\%$ within group & $100.0 \%$ & $50.0 \%$ & $100.0 \%$ & $83.3 \%$ \\
\hline \multicolumn{5}{|l|}{ Total } \\
\hline Count & 22 & 22 & 22 & 66 \\
\hline$\%$ within group & $100.0 \%$ & $100.0 \%$ & $100.0 \%$ & $100.0 \%$ \\
\hline \multicolumn{5}{|l|}{ Chi-square tests } \\
\hline & Value & & $p$-value & \\
\hline Fisher's exact test & 23.661 & & 0.000 & \\
\hline
\end{tabular}

\section{RASS scale}

RASS scale was monitored, showing the best recovery in the Fent group (Group B) (Table 5).

Table 5: Comparison between groups according to RASS scale

\begin{tabular}{llll}
\hline Study groups & \multicolumn{2}{l}{ RASS scale } & Maximum \\
\cline { 2 - 4 } & Median & Minimum & -1.0 \\
\hline Group & -2.0 & -2.0 & 0.0 \\
Dex group & 0.0 & -1.0 & -3.0 \\
Fentanyl group & -4.0 & -4.0 & \\
Combined group & & & \\
\hline
\end{tabular}

\section{Discussion}

In this study, patients were comparable regarding demographic data, ASA, and duration of surgery (Table 6). HR showed significant differences between the three study groups. Significant decrease following injection of the study drug was obvious in Group C (Dex-Fent) (Figure 1), which was maintained even during extubation and suctioning processes till 30 min following extubation.

Table 6: Comparison between groups according to age and duration of surgery

\begin{tabular}{|c|c|c|c|c|c|c|c|c|}
\hline & \multicolumn{6}{|c|}{ Group } & \multirow[t]{3}{*}{$F$} & \multirow[t]{3}{*}{ p-value } \\
\hline & \multicolumn{2}{|c|}{ Dex group } & \multicolumn{2}{|c|}{ Fentanyl group } & \multicolumn{2}{|c|}{ Combined group } & & \\
\hline & Mean & SD & Mean & SD & Mean & SD & & \\
\hline Age & 35.5 & 13.6 & 34.0 & 14.8 & 37.1 & 14.7 & 0.262 & 0.770 \\
\hline Duration & 2.5 & 0.4 & 2.5 & 0.5 & 2.6 & 0.4 & 0.255 & 0.776 \\
\hline
\end{tabular}

At the critical time of extubation, an increase of HR was the foremost in Group B (Fent group) and the least in Group C (Dex-Fent). Amutharani et al. (2019) [10] when compared dexmedetomidine $0.5 \mu \mathrm{g} \cdot \mathrm{kg}^{-1}$ infusion administered $10 \mathrm{~min}$ before tracheal extubation to fentanyl $1 \mu \mathrm{g} . \mathrm{kg}^{-1}$ infusion also located that dexmedetomidine group had a statistically significant lesser increase in HR than the fentanyl group during extubation and up to 100 min after extubation. On the contrary, Shrirang et al. (2015) [12] noticed the occurrence of tachycardia in 7\% of the study group received dexmedetomidine $0.5 \mathrm{ug} \cdot \mathrm{kg}^{-1}$ before extubation over $10 \mathrm{~min}$, which was not the case in our study. Tachycardia ( $20 \%$ increase from baseline) was only significant in Group B cases following extubation.

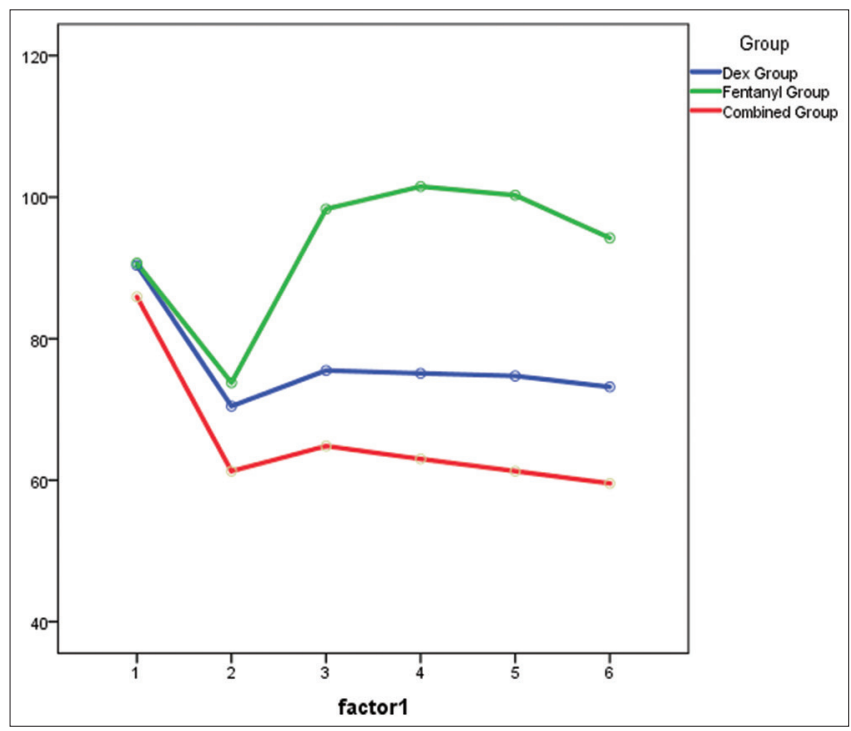

Figure 1: It showed what happened at the critical time \#3: Rise of heart rate more with fentanyl and least with the combined group

SBP (Figure 2) and DBP (Figure 3) showed an initial decrease within the three study groups following injection of the study drug. Following extubation, both SBP and DBP showed the highest readings within Group B, and it took $5 \mathrm{~min}$ after extubation to start to decrease again. While in both Groups A and C, SBP was maintained on the rock bottom side. Amutharani et al. (2019) [10] mentioned also that dexmedetomidine had the more significant control of SBP than the fentanyl group during extubation and up to 70 min after extubation and a lesser rise in DBP and mean blood pressure compared to the fentanyl group from $5 \mathrm{~min}$ before extubation to $130 \mathrm{~min}$ after extubation. Rani et al. (2016) [13] recorded a statistically significant drop in blood pressure at $5 \mathrm{~min}$ after test drug administration in both the groups; those receiving fentanyl $1 \mathrm{ug} / \mathrm{kg}$ compared with the dexmedetomidine 0.75 ug. $\mathrm{kg}^{-1}$, given $15 \mathrm{~min}$ before the end of surgery as an infusion over $5 \mathrm{~min}$, which we think that it was related to the rate of infusion. On the other hand, Üstün et al. (2006) [14] mentioned the incidence of a biphasic arterial blood pressure response; a shortlived increase in blood pressure and reflex decrease in pulse after injection of dexmedetomidine $4 \mathrm{ug} \cdot \mathrm{kg}^{-1}$ during intravenous conscious sedation in the third molar surgery which we guess that it may be related to the given higher dose of dexmedetomidine than in our study. 


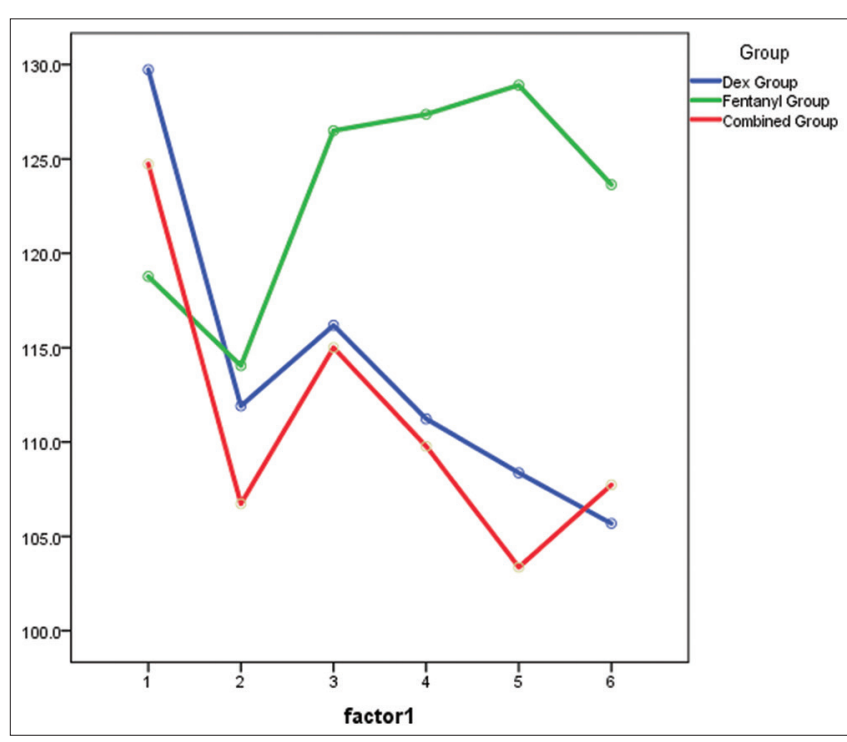

Figure 2: It showed that systolic blood pressure decreased $1 \mathrm{~min}$ after extubation in Dex and combined groups, but in fentanyl, it took 5 min to decrease

The time to extubation was significantly prolonged only within Group $\mathrm{C}$ in comparison with the opposite two groups, which may be due to the added effect of fentanyl and dexmedetomidine (Table 7). Aksu et al. (2009) [15] also found that dexmedetomidine $0.5 \mu \mathrm{g} \cdot \mathrm{kg}^{-1} \mathrm{IV}$, administered before extubation, was more effective in attenuating airway reflex responses to tracheal extubation and maintaining hemodynamic stability without prolonging recovery compared with fentanyl $1 \mu \mathrm{g} \cdot \mathrm{kg}^{-1} \mathrm{IV}$ in patients undergoing rhinoplasty. Fan et al. (2015) [6] compared remifentanil $0.03 \mu \mathrm{g} . \mathrm{kg}^{-1} \mathrm{~min}$, dexmedetomidine 0.5 $\mu \mathrm{g} . \mathrm{kg}^{-1}$, and dexmedetomidine $0.7 \mu \mathrm{g} . \mathrm{kg}^{-1}$ infusion for $10 \mathrm{~min}$ at end of otologic surgery and stated that the higher dose of dexmedetomidine $(0.7 \mu \mathrm{g} /$ $\mathrm{kg}$ ) was associated with a higher percentage of patients with smooth extubation and did not exhibit

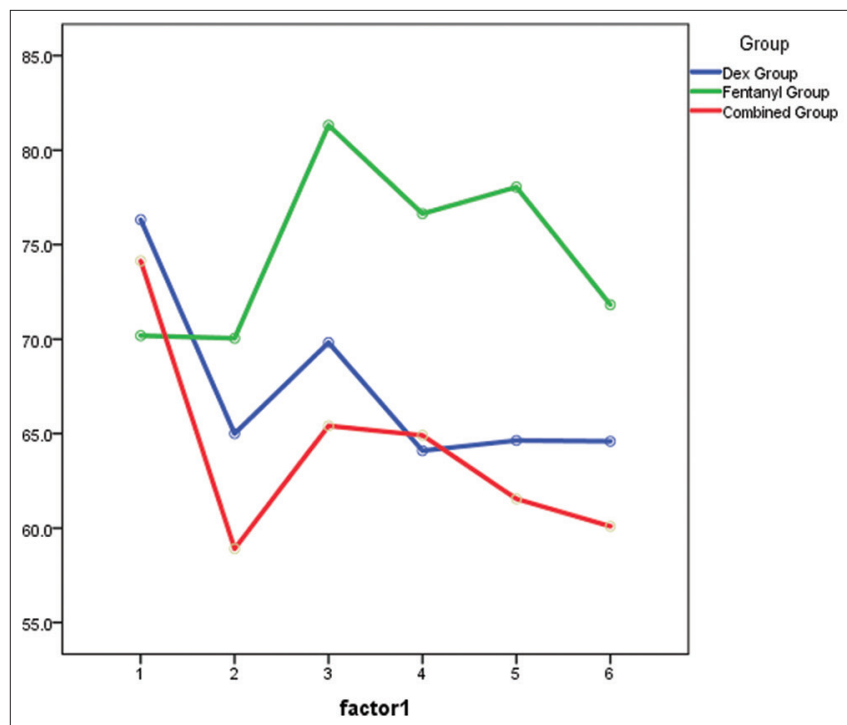

Figure 3: It showed changes in diastolic blood pressure in the three groups. The changes were of a similar pattern but smoother in the combined group a prolonged time to wake when it was compared to the other two groups. While Lee et al. (2015) [16] claimed that the addition of a single dose of dexmedetomidine $(0.5 \mathrm{ug} / \mathrm{kg})$ to a low-dose remifentanil infusion ( $\mathrm{TCl} 1$ $\mathrm{ng} \cdot \mathrm{ml}^{-1}$ ) resulted in delayed the time to awakening and extubation. This may be due to this combination of both drugs.

Table 7: Comparison between groups according to time and quality of extubation

\begin{tabular}{|c|c|c|c|c|c|c|c|c|c|}
\hline & \multicolumn{6}{|l|}{ Group } & \multicolumn{3}{|c|}{ Between groups } \\
\hline & \multicolumn{2}{|c|}{ Dex group } & \multicolumn{2}{|c|}{$\begin{array}{l}\text { Fentanyl } \\
\text { group }\end{array}$} & \multicolumn{2}{|c|}{$\begin{array}{l}\text { Combined } \\
\text { group }\end{array}$} & & & \\
\hline & Mean & sn & Mean & $\mathrm{SD}$ & Mean & $\mathrm{SD}$ & ANOVA & Chi_caura & $\mathrm{p}$-value \\
\hline Time to extub. & 18.0 & 2.0 & 15.5 & 0.9 & 21.1 & 2.4 & 37.308 & & $<0.001$ \\
\hline Quality of extub. & 2.3 & 0.5 & 3.5 & 0.5 & 2.4 & 0.5 & & 38.753 & $<0.001$ \\
\hline
\end{tabular}

A (Table 7) statistically significant difference between the three groups was present regarding the quality of extubation with no incidence of laryngospasm or bronchospasm within the three sample groups. The most favorable profile was seen within Group A having smooth extubation with minimal cough followed by Group C, with the remainder of cases within the previous two groups were experiencing moderate cough up to 3- or 4-fold following extubation improved after proper suctioning and were not related to any desaturation, laryngospasm, or bronchospasm. On the opposite hand, within Group B; quite half of the sample size developed a severe cough and strain up to 6 times, while the rest showed moderate cough up to 3 or 4 times. The quality of extubation score showed the most favorable profile within Group A. Aksu et al. (2009) [15] and Rani et al. (2016) [13] found the same; that is, extubation quality was found to be superior in dexmedetomidine group with patients arousable and tolerating suctioning and extubation compared with fentanyl group. Furthermore, Aksu et al. (2009) [15] mentioned that the fentanyl group had a prevalence of cough (70\%), $20 \%$ of which was severe. The lower prevalence of cough (15\%) found with dexmedetomidine compared with fentanyl suggests that dexmedetomidine

was more effective for improving the quality of extubation. Tung et al. (2020) [17] did a systematic review and metaanalysis of dexmedetomidine, remifentanil, fentanyl, lidocaine IV, intracuff lidocaine, and lidocaine through tracheal or topical route, demonstrated that in pairwise comparisons, all study medications were equivalent in reducing moderate and severe emergence coughing incidence, and were better than placebo or nothing.

Dexmedetomidine had the very best cumulative rank $(81.0 \%)$ for decreasing the incidence of moderate to severe peri-extubation coughing, followed by remifentanil $(67.2 \%)$, fentanyl $(66.2 \%)$, lidocaine intracuff $(59.5 \%)$, lidocaine TT/ topical (59.2\%), and lidocaine IV (52.4\%) therein order.

The level of sedation showed the most favorable picture in Group B, followed by Group A (Table 7). On the opposite hand, quite half Group C patients experienced deep sedation with the remainder of the sample size patients in moderate sedation post-extubation. 


\section{Conclusion}

Single-dose dexmedetomidine 1 ug. $\mathrm{kg}^{-1}$ given $15 \mathrm{~min}$ before extubation in chronic cigarette smoker undergoing elective surgery provided a better attenuation of the airway and cardiovascular responses to extubation and suctioning, and a better recovery profile when compared to fentanyl 1 ug. $\mathrm{kg}^{-1}$ along with improving quality of extubation. Dexmedetomidine $1 \mathrm{ug} . \mathrm{kg}^{-1}$ when mixed with fentanyl $1 \mathrm{ug} . \mathrm{kg}^{-1}$ also provided tight control on hemodynamics and airway responses to extubation comparable to the dexmedetomidine alone group but at the expense of prolonged time to extubation, post-operative sedation, and delayed recovery.

\section{References}

1. Perumal K, Mansor S. A synthesis of an aircraft approach, landing. J Mekanik. 2008;26(2):141-50.

2. Cavallone LF, Vannucci A. Review article: Extubation of the difficult airway and extubation failure. Anesth Analg. 2013;116(2):368-83. https:// doi.org/10.1213/ane.0b013e31827ab572

PMid:23302983

3. Parameswara G. Anesthetic concerns in patients with hyperreactive airways. Karnataka Anaesth J. 2015;1(1):8-16. https://doi.org/10.4103/2394-6954.149714

4. Gulsoy K, Deren S, Baskan S, Ornek D, Dikmen B. Cigarette smoking and the effect of dexmedetomidine and fentanyl on tracheal intubation. Rev Bras Anestesiol. 2012;62(2):141-53. https://doi.org/10.1016/s0034-7094(12)70114-9

PMid:22440371

5. Lemma DT, Alemnew EF, Gemeda LA, Goshu EM. Effects of lidocaine versus fentanyl on attenuation of hemodynamic responses to extubation after ear, nose and throat surgery in a resource limited setting: A prospective observational study. Int J Surg Open. 2020;24:129-35. https://doi.org/10.1016/j. ijso.2020.05.005

6. Fan $\mathrm{Q}, \mathrm{Hu} \mathrm{C}, \mathrm{Ye} \mathrm{M}$, Shen X. Dexmedetomidine for tracheal extubation in deeply anesthetized adult patients after otologic surgery: A comparison with remifentanil. BMC Anesthesiol. 2015;15(1):106. https://doi.org/10.1186/s12871-015-0088-7 PMid:26202786

7. Tung A, Fergusson NA, Ng N, Hu V, Dormuth C, Griesdale DG. Pharmacological methods for reducing coughing on emergence from elective surgery after general anesthesia with endotracheal intubation: Protocol for a systematic review of common medications and network meta-analysis. Syst Rev. 2019;8(1):32. https://doi.org/10.1186/s13643-019-0947-2

\section{PMid:30678727}

8. Gosai N, Jansari A, Solanki R, Patel D, Prajapati D, Patel B. A comparative study of the effect of dexmedetomidine and lignocaine on hemodynamic responses and recovery following tracheal extubation in patients undergoing intracranial surgery. Int J Basic Clin Pharmacol. 2015;4(2):371-5. https://doi. org/10.5455/2319-2003.ijbcp20150442

9. Faul F, Erdfelder E, Lang AG, Buchner A. G*power 3: A flexible statistical power analysis program for the social, behavioral, and biomedical sciences. Behav Res Methods. 2007;39(2):175-91. https://doi.org/10.3758/bf03193146

PMid:17695343

10. Amutharani $R$, Manoharan $T$, Manickavasagam $P$, Anandan $H$. Comparison of intravenous dexmedetomidine and intravenous fentanyl to attenuate the hemodynamic stress response to tracheal extubation. Indian J Clin Anaesth. 2019;6(2):242-7. https://doi.org/10.18231/j.ijca.2019.045

11. Sessler CN, Gosnell MS, Grap MJ, Brophy GM, O'Neal PV, Keane KA, et al. The richmond agitation-sedation scale: Validity and reliability in adult intensive care unit patients. Am J Respir Crit Care Med. 2002;166(10):1338-44. https://doi.org/10.1164/ rccm. 2107138

PMid: 12421743

12. Rao MS, Somasekharam $P$, Dinesh K, Ravi M. Effect of bolus dose of dexmedetomidine on hemodynamic responses and airway reflexes during tracheal extubation: Double blind, randomized, controlled trial study. World J Pharm Pharm Sci. 2015;4(3):731-40.

13. Rani $P$, Kumar VH, Ravishankar $M$, Sivashanmugam $T$, Sripriya R, Trilogasundary M. Rapid and reliable smooth extubation-Comparison of fentanyl with dexmedetomidine: A randomized, double-blind clinical trial. Anesth Essays Res. 2016;10(3):597-601. https://doi.org/10.4103/0259-1162.186605 PMid:27746558

14. Üstün $Y$, Gündüz M, Erdoğan Ö, Benlidayi ME. Dexmedetomidine versus midazolam in outpatient third molar surgery. J Oral Maxillofac Surg. 2006;64(9):1353-8. https://doi.org/10.1016/j. joms.2006.05.020

15. Aksu R, Akin A, Biçer C, Esmaoğlu A, Tosun Z, Boyaci A Comparison of the effects of dexmedetomidine versus fentanyl on airway reflexes and hemodynamic responses to tracheal extubation during rhinoplasty: A double-blind, randomized, controlled study. Curr Ther Res. 2009;70(3):209-20. https://doi. org/10.1016/j.curtheres.2009.06.003

PMid:24683231

16. Lee JS, Choi SH, Kang YR, Kim Y, Shim YH. Efficacy of a single dose of dexmedetomidine for cough suppression during anesthetic emergence: A randomized controlled trial. Can J Anesth. 2015;62(4):392-8. https://doi.org/10.1007/ s12630-014-0295-6 PMid:25523837

17. Tung A, Fergusson NA, Ng N, Hu V, Dormuth C, Griesdale DE. Medications to reduce emergence coughing after general anaesthesia with tracheal intubation: A systematic review and network meta-analysis. $\mathrm{Br} J$ Anaesth. 2020;124(4):480-95. https://doi.org/10.1016/j.bja.2019.12.041

PMid:32098647 